\title{
ПОРЯДОК ПОСТАНОВКИ ВОПРОСОВ ПРИСЯЖНЫМ И ВЫНЕСЕНИЯ СУДЕБНЫХ ПОСТАНОВЛЕНИЙ ОБ ОКОНЧАТЕЛЬНОМ РАЗРЕШЕНИИ УГОЛОВНЫХ ДЕЛ ПО СУДЕБНЫМ УСТАВАМ 20 НОЯБРЯ 1864 г.
}

Аннотация: Проведено исследование роли присяжных заседателей в постановлении приговоров по уголовным делам в рамках сравнительного анализа содержа-ния и правил вынесения приговоров коронного суда с участием и без участия присяжных в ходе судебной реформы 1864 г. В качестве основы для сравне-ния приговоров была избрана проиедура разрешения уголовных дел по пер-вой инстаниии в окружных судах России. Статья посвящена исследованию содержания и правил вынесения приговоров по уголовным делам в соответствии с Судебными уставами 20 ноября 1864 г. Методологическую основу исследования составили общефилософский, теоретический, эмпирический и диалектический методы, а так же методы анализа и аналогий. Автором установлено, что роль присяжных заседателей при постановлении приговоров по уголовным делам во многом определялась тем, что «судьям общественной совести» предоставлялось полное и безраздельное право ремать дело в соответствии со своим внутренним убеждением, которое не ограничивалось никакими, даже рекомендательными, правилами. Abstract: ПA research is conducted on the role of the jury in the court proceedings in criminal cases within a framework of a comparative analysis of the content and rules of rendering decisions in the Crown Tribunal with or without participation of jury in the course of Judicial Reforms of 1864. The basis for comparison of verdicts was the procedure of resolution of criminal cases by the first instance in the district courts of the Russian Federation. This article is dedicated to the research of the content and precepts of rendering court decisions in criminal cases in accordance with the judicial statutes of November 20, 1864. The author determines that the role of the members of the jury in rendering decisions in criminal cases was mostly defined by the fact that the "judges of the social conscience" had a full and absolute power to rule on a case based on their own inner belief, which was not limited by any, even recommended rules. Ключевые слова: Уголовный прочесс, уголовное дело, суд присяжных, приговор, постановка вопроса присяжным, судебное рассмотрение деяния, мера наказания, снисхождение, приговоры коронного суда, окружные суды.

Keywords: Criminal procedure, criminal case, jury trial, verdict, trial, legal penalty, leniency, verdicts of the Crown Tribunal, district courts.

риговор по уголовному делу являлся одновременно кульминацией и целью судебного рассмотрения деяния, вменяемого подсудимому в вину. Приговором давались окончательные ответы на вопросы о том, существовало ли событие преступного деяния, совершил ли его подсудимый, виновен ли подсудимый в совершении данного преступления и если виновен, то заслуживает ли по обстоятельствам дела снисхождения в решении своей участи. Кроме того, при установлении вины подсудимого, в приговоре четко определялась мера ответственности, иными словами, абстрактная санкция уголовной статьи в приговоре конкретизировалась в форме строго установленных вида и меры наказания, применявшейся к осужденному.

В рамках исследования роли присяжных заседателей в постановлении приговоров по уголовным делам особое значение имеет сравнительный анализ содержания и правил вынесения приговоров коронного суда, разрешавшего дела без участия присяжных заседателей, и коронного суда, разрешавшего дела с участием присяжных заседателей. В качестве основы для сравнения вышеуказанных приговоров нами был избрана процедура разрешения уголовных дел по первой инстанции в окружных судах. Именно здесь были сопоставимы условия деятельности суда, состоящего исключительно из «юридических элементов», и суда, «включающего, помимо, юридического, еще и народнический элемент» ${ }^{1}$

Форма приговора, постановляемого окружным судом по делам, разрешавшимся с участием и без участия присяжных заседателей, имела как общие, так и отличные признаки. Например, и в том, и в другом случае по итогам судебного рассмотрения дела составлялся специальный вопросный лист, который следует рассматривать как своеобразный фундамент приговора.

Вопросный лист играл существенную роль в уголовном процессе второй половины XIX - начала XX века, т.к. был неотъемлемой частью процесса с как участием, так и без участия, присяжных и позволял сосредоточить внимание участников процесса и, в первую очередь, коронных судей, а также присяжных, если речь шла о рассмотрении дела в суде присяжных, на первостепенных обстоятельствах дела; ограничивать приговор только обстоятельствами, которые были предметом судебного рассмотрения и, по этой причине,

\footnotetext{
${ }^{1}$ Гогель С.К. Общие замечания / Устав уголовного судопроизводства: Систематический комментарий / Под ред. М.Н. Гернета. М., 1915. Вып. IV. C. 1236.
} 
История государства и права

стали основой вопросного листа; фиксировать мнение судей по рассматриваемому делу, в том числе и мнение присяжных, если последние участвовали в слушании дела.

Постановкой вопросов и ответами на них достигалась главная цель судебного рассмотрения уголовного дела разрешение вопроса о виновности подсудимого 2 . Вопросы ставились по существенным признакам преступления, под которыми понимались такие признаки, «без которых преступление немыслимо»³. По мнению В.Н.Палаузова, к признакам, по которым формулировались вопросы по итогам судебного рассмотрения уголовного дела в суде, относились квалифицирующие обстоятельства, которые были «точно определены законом в своем составе» 4 .

На важность вопросного листа, как элемента процессуальной формы указывает, в частности, факт, что «большая часть кассационных жалоб и протестов по делам как с участием, так и без участия присяжных заседателей, касалась неправильной постановки вопросов» ${ }^{5}$. В течение только нескольких лет судебной реформы Сенат в кассационном порядке отменил около полутора сотен приговоров «в виду неправильной, по мнению Сената, постановки вопросов».

Основанием для постановки вопросов по итогам рассмотрения уголовного дела, согласно статье 751 уст. угол. суд., должны были служить не только выводы обвинительного акта, но также судебное следствие и заключительные прения, «в чем они развивают, дополняют или изменяют те выводы». Поэтому нормы Судебных уставов определяли, что постановка вопросов присяжным должна следовать по окончании судебного следствия и прений сторон.

Согласно ст. 754 уст. угол. суд., в вопросном листе ставились вопросы по рассматриваемому уголовному делу относительно существования события преступного деяния; совершения его подсудимым; виновности подсудимого в совершении вменяемого преступного деяния; наличия оснований для снисхождения или особого снисхождения при назначении подсудимому меры наказания.

Иными словами, вопросы суда по уголовному делу условно делились на две основные группы: «о действительности события, подавшего повод к обвинению», т.е. имел ли место сам факт преступления, и «о вине или невиновности подсудимого» ${ }^{6}$.

Основу вопросного листа составлял главный вопрос, в котором описывалось событие преступления и указывалась роль подсудимого в его совершении. При ответе на данный вопрос коронным судьям или присяжным предлагалось установить действительность события преступления, доказанность совершения его подсудимым и определить, может ли данное деяние быть поставлено подсудимому в вину.

Порядок постановки главного вопроса регулировался ст. 754 уст. угол. суд. В этой статье указывалось, что глав-

\footnotetext{
${ }^{2}$ Гогель С.К. Указ. соч. Там же.
}

${ }^{3}$ Селитренников M. О постановке вопросов на суде уголовном по решениям кассационного сената. СПб., 1875. С. 22.

${ }^{4}$ Палаузов В.Н. Постановка вопросов присяжным заседателям по русскому праву: сравнительное исследование. Одесса, 1885. С. 139.

${ }_{5}^{5}$ Волжин В. О постановке вопросов на суде // Журнал гражданского и уголовного права. 1888. Кн. 3. С. 14.

${ }^{6}$ Коротких М.Г. Самодержавие и судебная реформа 1864 года в России. Воронеж, 1989. С. 134. ный вопрос должен быть один. По мнению некоторых авторов, это положение было призвано устранить «возможность противоречивых ответов, неизбежно появляющихся при нескольких вопросах» ${ }^{7}$.

Однако при сомнении в действительности какого-либо обстоятельства по делу главный вопрос подразделялся на несколько составных частей. В результате вниманию коронных судей или присяжных заседателей предлагались отдельные вопросы соответственно о событии преступления, деянии подсудимого и вменении деяния подсудимому в вину.

По смыслу ст. 754 уст. угол. суд. отдельный вопрос о событии преступления ставился лишь по ходатайству сторон. Однако Сенат предусмотрел два случая, когда отдельный вопрос о событии ставился обязательно:

1. При обвинении пособников, если не был установлен исполнитель преступления.

2. Для защиты интересов гражданского истца в уголовном деле.

Вопрос о событии преступления начинался словами «Доказано ли..», после которых следовало описание факта, положенного в основу обвинения. Например, по делу об умышленном поджоге мельницы подобный вопрос был следующим: «Доказано ли, что в ночь с 1 на 2 февраля 1875 года был совершен поджог паровой мельницы, ... отчего мельница эта и сгорела?»

Однако возможность постановки отдельного вопроса о событии преступления вызвала неодобрительные оценки в среде правоведов. На взгляд одного из исследователей данной проблемы В.Волжина, постановка такого вопроса лишь дискредитировала органы дознания, предварительного следствия и собственно суда9. При отсутствии состава преступления или по недоказанности его события данные органы имели достаточно средств для прекращения дела до разрешения его судом. В итоге постановка такого вопроса, по сути, провоцировала судейский состав к необоснованному оправданию подсудимого по причине сомнений в профессионализме следственных и прокурорских деятелей. Поэтому В.Волжин выступал за отмену отдельного вопроса о событии, допуская его лишь в двух случаях: при сомнении во вменении преступления и по просьбе гражданского истца.

Существовала и более радикальная точка зрения на выделение вопроса о событии. Например, В.Д.Спасович совершенно исключал постановку вопроса о событии даже по требованию гражданского истца, оставляя основанием этого вопроса лишь сомнение во вменении. При этом В.Д.Спасович указывал, что, решая вопрос о событии, поставленный отдельно лишь по настоянию гражданского истца в уголовном деле, судьи, рассматривавшие данное уголовное дело, вторгались бы в компетенцию гражданского суда $^{10}$. При этом В.Д.Спасович подчеркивал, что в распоряжении истца находились все средства защиты своих прав в гражданском судопроизводстве.

\footnotetext{
${ }^{7}$ Устав уголовного судопроизводства: Систематический комментарий / Под ред. М.Н. Гернета. М., 1915. Вып. IV. С. 1254

${ }^{8}$ Русские судебные ораторы в известных уголовных процессах ХІХ века. Тула, 1997. С. 203.

${ }^{9}$ См.: Волжсин В. О постановке вопросов на суде ... С. 38.

${ }^{10}$ См.: Спасович В.Д. О постановке вопросов присяжным ... С. 29.
} 


\section{Право и политика $12(180) \cdot 2014$}

Вопрос о совершении преступления подсудимым формулировался посредством развернутого указания в главном вопросе всех имен, отчеств и фамилий подсудимого, его возраста, сословной принадлежности и места жительства. Поэтому в начале каждого главного вопроса указывалось, что обвиняется «крестьянин деревни Ханеневки, Мариинской волости, Саратовского уезда Игнатий Степанов Васильев, он же Матутин, 21 года, в том, что...»".

Сведения, индивидуализирующие подсудимого, практически в неизменном виде воспроизводились в вопросном листе из обвинительного акта. Для сравнения можно привести заголовок обвинительного акта по делу крестьянина Б.Я. Филатова: «Обвинительный акт, коим предполагается предать суду Саратовского Окружного Суда с участием Г.г. Присяжных Заседателей крестьянина Саратовской губернии, Вольского уезда, деревни Елховки Бориса Яковлева Филатова, 50 лет, состоящего под полицейским надзором...» ${ }^{12}$ и выдержку из главного вопроса присяжным: «Виновен ли крестьянин д. Елховки, Вольского Уезда, Борис Яковлев Филатов, 50 лет, в том, что...» $»^{13}$.

Таким образом, персонализация подсудимого в обвинительном акте была практически тождественна формулировке вопросного листа, что раскрывает одно из процессуальных предназначений обвинительного акта - быть своеобразным фундаментом при составлении вопросного листа и, соответственно, приговора по уголовному делу.

Значение вопроса о совершении преступления именно подсудимым состояло в индивидуализации главного вопроса, что было особенно важно при рассмотрении дел о соучастии. По каждому из соучастников ставился отдельный главный вопрос и, соответственно, количество главных вопросов равнялось числу соучастников ${ }^{14}$. При отсутствии распределения ролей между соучастниками вопросы содержали одинаковое описание преступного деяния и отличались друг от друга только набором признаков, персонифицирующих того или иного соучастника.

При составлении вопросного листа едва ли не главной была проблема емкого и, в то же время, понятного присяжным формулирования вопросов. Согласно статье 760 уст. угол. суд. вопросы должны были формулироваться так, чтобы, с одной стороны, быть доступными для понимания присяжных, а с другой - охватывать все признаки состава преступления, предусмотренные статьей материального уголовного закона. Последнее было необходимо коронным судьям, которые квалифицировали деяние подсудимого и выносили приговор на основе признаков преступления, описанных в вопросном листе.

Главным пунктом, определяющим отличие вопросов, которые разрешались коронными судьями, от вопросов, подлежавших разрешению в суде присяжных, были требования ст. 760 уст. угол. суд. Дело в том, что присяжные были судьями непрофессиональными и не могли оперировать юридическими терминами так же свободно, как это делали

\footnotetext{
${ }^{11}$ ГАСО. Ф. 8. ОП. 1. Д. 541. Л. 458

${ }^{12}$ ГАСО. Ф. 8. ОП. 1. Д. 25. Л. 121.

${ }^{13}$ ГАСО. Ф. 8. ОП. 1. Д. 541. Л. 44.

${ }^{14}$ См.: Жижиленко А. Голосование уголовного суда / Словарь юридических и государственных наук. СПб,. 1901. Т. 2. Вып. IV. С. 166.
}

коронные судьи. Поэтому статья 760 уст. угол. суд. требовала, чтобы в вопросах присяжным квалифицирующие признаки описывались в виде общеупотребительных выражений, а не принятых в законе определений.

Таким образом, все юридические термины должны были заменяться подробными объяснениями, состоящими из бытовых фразеологических оборотов, иначе присяжные - судьи непрофессиональные - могли не понять смысл вопросов и вынести несправедливый вердикт.

Руководствуясь правилами ст. 760 уст. угол. суд., крайне трудной для соблюдения в судебном разбирательстве, суды были вынуждены давать толкование всем юридическим терминам вопросного листа, даже таким, которые, хотя и являлись общеупотребительными, но были включены в статьи материального закона и, в силу этого, формально относились к юридическим. В результате понятные даже несведущему в юриспруденции слова, как, например, «кража», в вопросных листах заменялись малопонятными выражениями «тайное похищение» ${ }^{15}$ и т.п.

Правила формулирования вопросов в общеупотребительных выражениях, специально разработанные законодателем для того, чтобы вопросы были полностью понятны присяжным, на практике привели к обратному эффекту. Вопросы присяжным были лишены должной краткости, излагались в длинных периодах, в распространенной описательной форме, со многими придаточными предложениями, дополняющими одно другое и затемняющими смысл всего вопроса.

Очевидно, что во избежание громоздкости и непонятности вопросов следовало признать некоторые юридические термины, такие как «кража», «взлом», «убийство» и др., общеупотребительными, каковыми они на самом деле и являлись. Однако в этом случае неизбежно возникала проблема, какие юридические термины считать общеупотребительными?

Составить исчерпывающий перечень юридических терминов, претендовавших называться общеупотребительными, было практически невозможно. Значение некоторых терминов (разбой, покушение и т.п.) могло быть понятно большинству, но не всем. Поэтому целесообразность официального разграничения юридических терминов на общеупотребительные и все другие, а также сама необходимость составления такого списка представлялась сомнительной, так как среди присяжных мог оказаться человек, не знакомый с общеизвестным юридическим термином или понимавший его по-своему. Вердикт такого присяжного, конечно, не мог считаться справедливым.

Правоведы того времени предпринимали попытки разрешить проблему формулировки вопросного листа. Так, например, Г.Шатров указывал, что судить о том, какие термины вызывают недоумение присяжных, и объяснять эти термины присяжным вполне мог бы и председательствующий ${ }^{16}$. В.Волжин также настаивал на необходимости объяснения терминов председателем ${ }^{17}$.

\footnotetext{
${ }^{15}$ Хрулев С.С. Суд присяжных (очерк деятельности судов и судебных порядков). // Журнал гражданского и уголовного права. 1886. Кн. 10. C. 71 .

${ }^{16}$ См.: Шатров Г. Указ. соч. С. 824.

${ }^{17}$ См.: Волюсин В. Возражение Г.А.Вульферту на его статью о постановке вопросов в февр. кн. «Юрид. Вестника» за 1891 год // Судебная газета. 1891. № 20. С. 4.
} 
История государства и права

Сенат, как орган, призванный оптимизировать судебную деятельность, оказался не на высоте своей задачи. Он не только не стремился упростить правила постановки вопросов присяжным, но, напротив, требовал от судов строжайшего соблюдения положений о замене юридических терминов на общеупотребительные. Сенат при этом руководствовался своими взглядами на существо суда присяжных.

Особенностью практики российского суда присяжных было расхождение разработчиков норм Судебных уставов и кассационной практики Сената во взглядах на присяжных. Если Судебные уставы исходили из того, что присяжные являются судьями в полном смысле этого слова, и предоставляли присяжным разрешать вопросы и факта, и права, то Сенат признавал за присяжными возможность решать, лишь вопросы факта.

Поэтому своей практике Сенат придерживался правила постановки вопросов присяжным только по фактическим признакам преступления, не затрагивая юридической стороны дела, и придерживался тенденции кассационной отмены приговоров, в основе которых лежали вопросы, не соответствующие этому правилу.

Кассационная практика Сената существенно усложняла процедуру составления вопросного листа, делая вопросы присяжным неоправданно громоздкими и порой непонятными. Так, по делу о похищении денег из ящика в церкви приговор был отменен в кассационном порядке только из-за указания в вопросе присяжным, что «деньги принадлежали церкви». С точки зрения кассационного департамента, такая формулировка была недопустима, потому что вопрос о «принадлежности» являлся юридическим обстоятельством, не подлежащим рассмотрению присяжных. По мнению Сената, правильнее было бы записать в вопросе, что «деньги эти были записаны на приходе, или что они были выручены от продажи свеч»» ${ }^{18}$, на основании чего суд впоследствии и должен был заключить, что деньги принадлежали церкви.

Таким образом, громоздкость и запутанность вопросов присяжным возникали вследствие противоречащего духу Судебных уставов мнения Сената, что присяжные являлись исключительно судьями факта, и соответствующего требования заменять каждый юридический термин описанием в общеупотребительных выражениях.

Очевидно, что главную роль в упрощении редакции вопросов и облегчении их понимания присяжными должны были сыграть, во-первых, отказ законодателя и судебных деятелей от взгляда на присяжных исключительно как на судей факта, а во-вторых, замена юридических терминов на общеупотребительные выражения только по мотивам целесообразности такой замены. Критерием целесообразности могло быть мнение председательствующего, сложившееся на основе опроса присяжных о необходимости развернутого изложения юридических терминов.

В целом следует отметить, что вопросный лист имел определяющее значение для разрешения уголовных дел, т.к. приговор, постановлявшийся как судом, в составе коронных судей, так и судом, представленным коронными судьями с участием присяжных заседателей, должен был точно соответствовать по своему содержанию вопросам и ответам, изложенным в данном листе (ст.ст. 825-826 уст. угол. суд.).

${ }^{18}$ Трегубов С.Н. Указ. соч. С. 64
Впоследствии на необходимость строгого соблюдения положений, изложенных в данных нормах, неоднократно обращал внимание судебных органов Сенат, который, помимо всего прочего, указывал также и на недопустимость постановления приговоров по обстоятельствам, не включенным в вопросный лист ${ }^{19}$.

Помимо вопросного листа, содержание приговора определялось и рядом других законодательных требований. По делам, решавшимся без участия присяжных заседателей, закон допускал первоначальное постановление приговора в виде краткой резолюции по делу (ст. 788 уст. угол. суд.). Содержание резолютивной части составляли сведения о времени судебного заседания; о составе присутствия суда; краткое изложение обстоятельств дела с выводами суда о виновности либо об оправдании подсудимого и о назначенной последнему меры наказания в случае признания виновным.

Закон устанавливал, что постановление приговора в окончательной форме должно было состояться не позднее, чем по истечении двух недель после вынесения краткой резолюции по делу (ст.ст. 793, 797 уст. угол. суд.). В полном приговоре, помимо вышеприведенных сведений, должны были содержаться данные «о предмете обвинения, выведенные в обвинительном акте или жалобе частного обвинителя и в заключительных по судебному следствию прениях; соображения обвинения как с представленными по делам доказательствами и уликами, так и с законами; подробное изложение согласно с разумом и словами закона сущности приговора».

Содержание приговора по делу, разрешенному с участием присяжных, во многом было аналогично содержанию приговоров, постановленных без участия присяжных. Как и в вышеприведенном варианте, по итогам рассмотрения дела в суде присяжных суд выносил краткую резолюцию о виновности или оправдании подсудимого и был обязан изготовить приговор в окончательной форме не позднее, чем по истечении двух недель со дня окончания рассмотрения дела судом присяжных. Сведения, включавшиеся в данный приговор, соответствовали требованиям, предъявляемым к приговорам коронного суда без участия присяжных заседателей (ст. 826 уст. угол. суд.).

Тем не менее, главным отличием приговора, постановленного в суде присяжных, было отсутствие мотивировочной части, т.е. раздела приговора, в котором указывается на логические связи между обстоятельствами дела, рассмотренными во время слушания, и выводами суда о наличии либо отсутствии виновности подсудимого. С.И.Викторский так объяснял отсутствие мотивировочной части: «Присяжные, будучи совершенно способны здраво обсуждать обстоятельства и решать предлагаемые им вопросы, не могут, все-таки, почитаться таковыми, коим можно вменять в обязанность подробно излагать мотивы своего решения... немотивирование присяжными своих вердиктов дает им возможность не стесняться формальными определениями закона и толковать их более соответственно с выработанными жизнью правилами» ${ }^{20}$.

Правила внутреннего убеждения или, как они были обозначены в законе, общие основания к суждению о силе

\footnotetext{
${ }^{19}$ См.: Собрание узаконений и распоряжений правительства. СПб., 1866. № 88. Ст. 203; 1867. № 190. Ст. 84.

${ }^{20}$ Викторский С.И. Русский уголовный процесс. М., 1997. С. 410
} 
DOI: $10.7256 / 1811-9018.2014 .12 .13756$

При цитировании этой статьи сноска на dоі обязательна

\section{Право и политика $12(180) \cdot 2014$}

доказательств, доводились до сведения присяжных председательствующим в напутственном слове.

Учение о доказательствах не было известно присяжным, поэтому присяжные нуждались в ознакомлении с ним, чтобы приговор был справедлив. По мнению А.Ф. Кони, помощь председателя в обобщении нередко многосложного материала, выясненного на судебном следствии, имела весьма полезное и существенное для присяжных значение ${ }^{21}$. Но здесь следует иметь в виду, что разъяснения, касающиеся доказательств, могли быть двоякого рода: говоря, например, о силе свидетельских показаний, председатель может указать вообще, что для определения значения того или другого свидетельского показания присяжные должны обсудить: а) имел ли свидетель возможность знать, о чем он показывает, то есть степень близости свидетеля к событию и обстановку, среди которой совершалось наблюдение (дальность расстояния, ночное время и т.п.); б) был ли свидетель способен понять совершавшееся перед ним и насколько он способен изложить понятое, то есть значение преходящих и постоянных индивидуальных свойств свидетеля (близорукость, память, волнение и т.п.); в) имеет ли свидетель желание сказать правду, то есть отношение свидетеля к обвиняемому, здесь особое значение приобретают, например, характер свидетеля (склонность к преувеличению), репутация его, насколько это выяснилось из дела (если, к примеру, свидетель уже раз обвинялся в лжесвидетельстве). Все это председатель мог высказать перед присяжными не касаясь личности свидетеля по данному делу и, видимо, такой способ объяснения правил о силе доказательств предпочтительнее, нежели тот, при котором эти правила применяются к конкретным свидетелям по данному делу, ибо дает возможность председателю быть беспристрастнее и не касаться фактической стороны дела, выхватывая из него по своему усмотрению то или другое обстоятельство.

Составители Судебных уставов 1864г. положились на опыт председателей и не дали общих оснований для оценки доказательств. Но эти основания, хотя бы самые общие, должны были, по мнению некоторых дореволюционных авторов, быть включены в российское законодательство. Во первых, весьма важным условием правильного отправления правосудия является «предупреждение судейского произвола в оценке доказательств и обеспечение такого положения вещей, при котором эта оценка производилась бы по всем делам единообразно и имела бы качество устойчивости» ${ }^{22}$. Во вторых, критерии достоверности доказательств должны были излагаться присяжным таким образом, чтобы им было известно, что даже при системе внутреннего убеждения законодатель различал более или менее достоверные доказательства.

Необходимо согласиться с замечаниями некоторых исследователей суда присяжных, что «правильно преподанные общие руководящие указания к суждению о силе доказательств составляют одну из главных гарантий правильности вердикта, а указания неверные должны быть признаны кассационным поводом» ${ }^{23}$. Главным правилом председательствующего при составлении и произнесении напутствия было свести к минимуму влияние своего мнения на мнение присяжных. Малейшее отступление от этого правила приводило к несправедливым вердиктам и отменам приговоров.

Таким образом, роль присяжных заседателей при постановлении приговоров по уголовным делам во многом определялась тем, что законодатель предоставил «судьям общественной совести» полное и безраздельное право решать дело в соответствии со своим внутренним убеждением, которое не ограничивалось никакими, даже рекомендательными, правилами.

\section{Библиография:}

1. Собрание узаконений и распоряжений правительства. СПб., 1866. № 88. Ст. 203; 1867. № 190.

2. Русские судебные ораторы в известных уголовных процессах ХIX века. Тула, 1997.

3. Фойницкий И.Я. Курс уголовного судопроизводства. СПб., 1896. Т.2. С

4. Викторский С.И. Русский уголовный процесс. М., 1997.

5. Устав уголовного судопроизводства: Систематический комментарий / Под ред. М.Н. Гернета. М., 1915. Bып. IV.

6. Коротких М.Г. Самодержавие и судебная реформа 1864 года в России. Воронеж, 1989.

\section{References (transliterated):}

1. Foinitskii I.Ya. Kurs ugolovnogo sudoproizvodstva. SPb., 1896. T.2. S

2. Viktorskii S.I. Russkii ugolovnyi protsess. M., 1997.

3. Korotkikh M.G. Samoderzhavie i sudebnaya reforma 1864 goda v Rossii. Voronezh, 1989.

\footnotetext{
${ }^{21}$ Протокол заседания уголовного отделения юридического общества при Санкт-Петербургском университете от 21 мая 1877 г. // Журнал гражданского и уголовного права. Спб., 1878. Кн. 1. С. 30.
}

\footnotetext{
${ }_{22}$ Фойниџкий И.Я. Курс уголовного судопроизводства. СПб. 1896. T.2. C. 184.

${ }^{23}$ Василенко И.Г. Заключительное слово председателя в суде присяжных: исследование сравнительно-догматическое. СПб. 1878. С. 78.
} 